УДК 371.382

DOI 10.37386/2413-4481-2020-3-14-20

Т.А. Кулакова

Алтайский государственный педагогический университет, г. Барнаул, Россия КРЕОЛИЗОВАННЫЙ ТЕКСТ ИНСТРУКЦИИ НАСТОЛЬНОЙ ИГРЫ
КАК МОТИВАЦИОННЫЙ ИНСТРУМЕНТ СОВРЕМЕННОГО УЧИТЕЛЯ

В статье раскрывается проблематика креолизации текста, описываются основные характеристики инструкции настольной игры как негомогенного, гибридного текста. На конкретных примерах анализируются разнообразные невербальные компоненты инструкции, такие как графическое оформление текста, иллюстрации, фотографии, схемы, видео, используемые как по отдельности, так и в сочетаниях друг с другом, а также функции, выполняемые этими элементами. В данной работе рассматриваются условия, позволяющие относится к инструкциям настольных игр как к мотивационному инструменту при обучении школьников.

Ключевые слова: креолизованный текст, поликодовый текст, инструкция, мотивация, невербальный компонент, функции текста.

T.A. Kulakova

Altai State Pedagogical University, Barnaul, Russia

\title{
BOARD GAME RULES CREOLIZED TEXT AS A MOTIVATION TOOL OF A MODERN TEACHER
}

\begin{abstract}
The article focuses on creolized text in general and describes the main features of board games rules as inhomogeneous texts belonging to this type. The article supplies the examples of nonverbal elements used in board games rules such as graphic design of the verbal part of the text, different pictures, photos, schemes and video. Creolized texts of board games rules may contain only one nonverbal element or there may be a combination of them. This research considers the functioning of such texts and the possibility for them to be used as a motivational means while teaching children.

Key words: creolized text, polycode text, board games rules, motivation, nonverbal element, text functions.
\end{abstract}

Время устанавливает правила, диктует условия успешности образовательного процесса, вот потому в арсенале современного учителя и преподавателя уже давно не только учебник. На помощь призывается все, что может смотивировать, заинтересовать, увлечь ученика предметом.

Настольные игры в первом ряду таких учительских помощников. И это неудивительно: они делают занятие динамичнее, необычнее, используемый словарь (в случае преподавания иностранного языка) - богаче, разнообразнее, а овладение новыми знаниями - естественнее и даже азартнее. Сами игры уже давно в поле зрения исследователей от образования: изучаются механизмы коммуникации игроков, модели их взаимодействия, развивающий потенциал самих игр и т. д., однако один из компонентов игры долгое время совершенно напрасно оставался без должного внимания. Речь идет об инструкции, ведь то, как именно она изложена, как оформлена, влияет не только на успешность процесса самой игры, но и на то, состоится ли она в принципе.

В нашем исследовании мы обратились к инструкциям русскоязычных и англоязычных настольных игр. В фокусе оказались прежде всего не дидактические игры, то есть те игры, в которые дети могут играть на уроке, но без помощи учителя, и вне урока, самостоятельно, с друзьями или семьей. Свою образовательную и мотивирующую функцию такие игры будут выполнять и в отсутствии направляющей помощи учителя. Все будет зависеть от того, насколько удачно составлена инструкция к игре, при условии, конечно, что сама игра интересна и достойна детского (или студенческого) внимания.

Для подобного рода текстов основной функцией, по классификации К. Бринкера [1], является функция апеллятивная. Очевидно, что не все инструкции способны выполнять ее одинаково, т. е. имеются особые характеристики инструкций, наличие которых будет обеспечивать выполнение 
основной функции наилучшим образом. Такими чертами инструкции являются именно те ее особенности, что позволяют отнести тексты такого рода к креолизованным текстам.

Однако сначала следует разобраться, что подразумевается под креолизованными текстами. В отношении подобных структур, организованных на основе комбинации естественного языка с элементами других знаковых систем, пока не было выработано единого и общепринятого термина. В работах современных лингвистов для обозначения синтеза вербальных и невербальных компонентов текста используются такие термины, как «изовербальный комплекс» [2], «изоверб» [3], «семиотически-осложненный текст» [4], «лингвовизуальный комплекс» [5], «видеовербальные тексты» [6]. Помимо указанных выше, многими исследователями используется термин «поликодовый текст», который противопоставляется тексту монокодовому. К поликодовым текстам относят «случаи сочетания естественного языкового кода с кодом какой-либо иной семиотической системы (изображение, музыка и т. п.)» [7, с. 107]. Несмотря на такое терминологическое разнообразие наибольшее распространение и признание получил термин «креолизованный текст», введенный психолингвистами Е.Ф. Тарасовым и Ю.А. Сорокиным. Они определяли креолизованные тексты как «тексты, фактура которых состоит из двух негомогенных частей: вербальной (языковой/ речевой) и невербальной (принадлежащей к другим знаковым системам, нежели естественный язык)» [8, с. 180-181].

В данной работе мы будем использовать термин «креолизованный» и придерживаться определения, данного Ю.А. Сорокиным и Е.Ф. Тарасовым.
Креолизованный текст характеризуется, в первую очередь, своей целостностью и связанностью, он может существовать в коммуникации любого вида в качестве структурированного целого и регулирует отношения на уровне формы и контента. Целостность текста обеспечивается единой темой, которая раскрывается вербальными, иконическими и другими паралингвистическими средствами, то есть коммуникативно-когнитивной установкой. По мнению А.Р. Габидуллиной, между изобразительной и вербальной частью существуют синсемантичные отношения: вербальная часть не существует отдельно от изобразительной части; она либо ориентирована на изображение, либо отсылает к нему, а изображение, в свою очередь, является обязательным элементом текста [9]. Таким образом, в подобных текстах вербальный и визуальный компоненты неразрывно связаны. При удалении одного из компонентов оставшийся либо перестает передавать информацию, делает ее неполноценной или вовсе интерпретируется иначе, то есть полноценная и эффективная передача информации возможна только при взаимодействии всех частей текста.

Инструкция к настольной игре, как и всякий негомогенный текст, характеризуется наличием в ней целого ряда невербальных компонентов. Наиболее часто текст инструкции к настольной игре креолизуется иллюстрациями. В первую очередь они призваны пояснить правила игры и полезны тогда, когда в игре много элементов, их точное расположение определенным образом имеет значение. За примерами обратимся к рисунку 1 (иллюстрация разъясняет один из моментов игры) и рисунку 2 (наглядно показано, как оперировать с элементами игры).

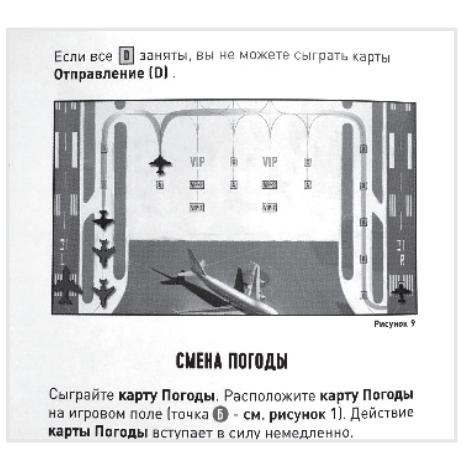

Рис. 1. Фрагмент инструкции настольной игры Хагена Темерязева «Взлет разрешен»
Говоря о включении в текст инструкции иллюстраций, следует отметить тот факт, что одной из основных целей, что преследует автор игры, является привлечение к игре внимания, возможность доставить играющим эстетическое удовольствие, или, что тоже значимо, еще до начала игры создать нужную атмосферу, погрузить игроков в тематику игры, если последняя не 
абстрактная. В подобных случаях целостность гибридного текста и взаимосвязь его компонен- тов проявляется особенно очевидно. Обратимся к рисункам 3 и 4.

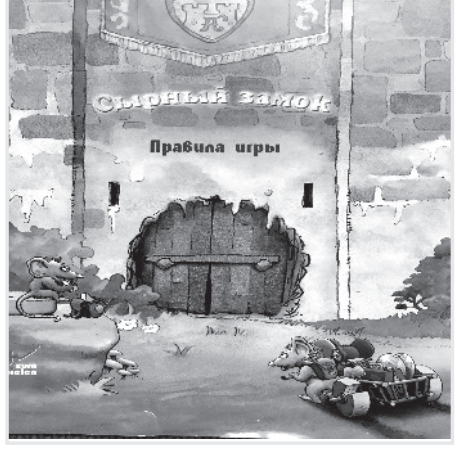

Рис. 3. Фрагмент инструкции настольной игры ЙенсаПетера Шлимана и Бернарда Вебера «Сырный замок»

Примечательно, что если игра адресована детям младшего возраста, может быть, даже не умеющим читать, то инструкция к ней все равно будет выполнена ярко, красочно, с иллюстрациями, ориентированными на возраст игроков. Таким образом, этот креолизованный текст находит «читателя» и в лице самых юных участников игры, пусть они смогут воспринять только лишь один из его компонентов. Эту ситуацию можно наблюдать на рисунке 3: возраст играющих, обозначенный автором, - 6 лет. Очевидно, что иллюстрации рассчитаны именно на детский возраст, хотя инструкцию читать будут родители или учителя, воспитатели.

Более взрослые игры также не лишены иллюстративного сопровождения, но цель тут уже другая - через инструкцию создать атмосферу и настроить на игру.

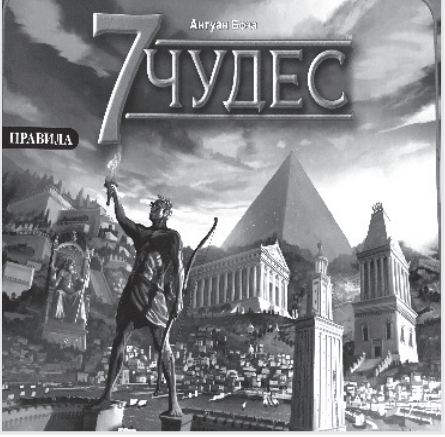

Рис. 4. Фрагмент инструкции настольной игры Антуана Боза «7 чудес»

Иногда картинки не просто дополняют текст правил, но и создают второй смысловой слой инструкции. Его предназначение отличается от цели основного слоя - он носит более развлекательный характер. В таких ситуациях в инструкцию привносятся персонажи, связанные с игрой опосредованно, которые комментируют правила, выражают свое к ним отношение, или вовсе с правилами несвязанные, но добавляющие инструкции целиком более развлекательный характер, что является прямым проявлением аттрактивной функции этого гибридного текста. Чаще всего подобный второй смысловой слой создается иллюстрациями, выполненными в виде комиксов. Такого рода использование иллюстраций в инструкции, как правило, не зависит от возраста участников, на который рассчитана игра, это зависит лишь от фантазии автора инструкции. Примеры представлены на рисунках 5 и 6.

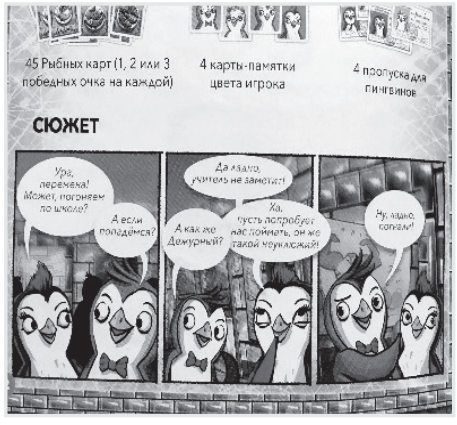

Рис. 5. Фрагмент инструкции настольной игры Брайана Гомеса «Айс-класс»

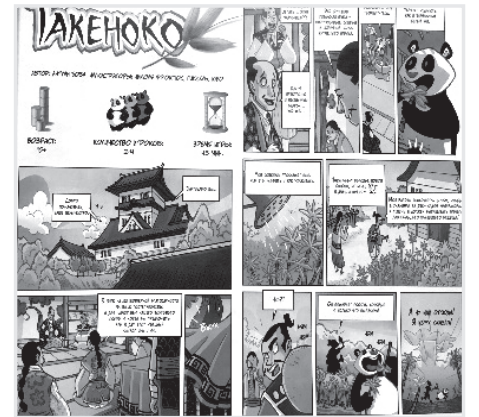

Рис. 6. Фрагмент инструкции настольной игры Антуана Боза «Такеноко»
Нередко инструкция содержит фотографии компонентов игры. Цель у таких фотографий та же, что и у иллюстраций - сделать тот или иной момент игры более понятным. Пошаговое фотосо- провождение позволяет сократить время, которое требуется на усвоение и запоминание правил, а также приходит на помощь непосредственно во время игры, когда правила забылись. Так их 
можно быстро восстановить, просто просмотрев фото и не перечитывая весь текст. Примеры фото- компонетов инструкции можно увидеть на рисунках 7 и 8.

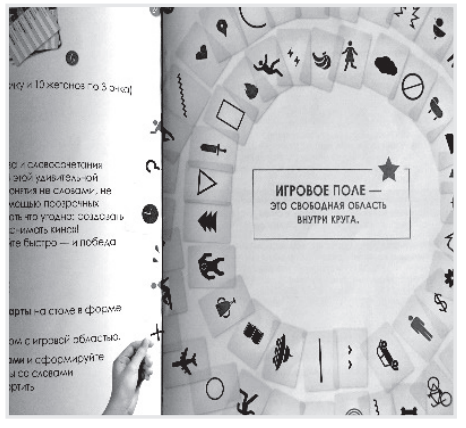

Рис. 7. Фрагмент инструкции настольной игры Шинго Фудзиты «Визуал»

На фотографии (рис. 7) показано, как должны располагаться игровые карточки, а на рисунке 8 на фото даны ответы, то есть указано, какие именно наборы должны собрать играющие. Использование именно фотографий, а не рисунков оправдано здесь как в никакой другой игре - это достаточно необычное мемори, участникам нужно собирать не пары, а тройки карточек, и картинки на них не идентичные, а содержат выполненные в разной технике изображения одного и того же предмета или животного.

Еще одним элементом креолизованного, негомогенного текста могут являться графики и

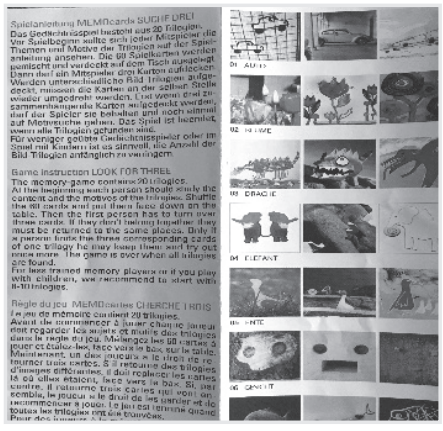

Рис. 8. Фрагмент инструкции настольной игры «SUCHE DREI Kleine Künstler»

схемы. Это утверждение справедливо и для инструкций к настольным играм - наличие подобных включений определяется предназначением текста в целом - снабдить игрока подробным, пошаговым руководством к действию. Примером может служить фрагмент инструкции, представленный на рисунке 9. Рисунок 10 - образец того, как схема в комбинации с фотографиями служит, чтобы помочь подготовить к игре игровое поле. Такое решение задачи инструктирования пользователя гораздо более эффективно и менее затратно по времени, по сравнению с монокодовой, вербальной инструкцией.

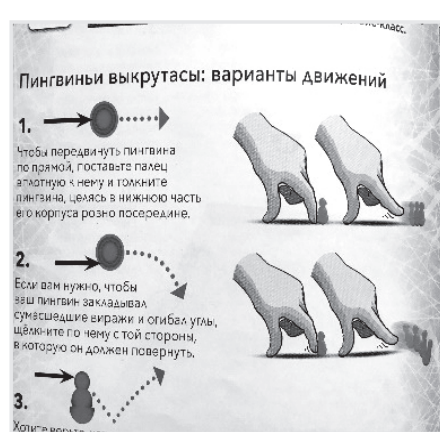

Рис. 9. Фрагмент инструкции настольной игры Брайана Гомеса «Айс-класс»

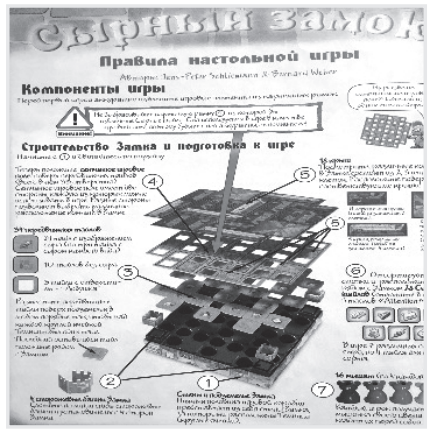

Рис. 10. Фрагмент инструкции настольной игры Йенса-Петера Шлимана и Бернарда Вебера «Сырный замок»
Проблема креолизованности текста стала вызывать особый интерес лингвистов достаточно недавно. Иллюстрации, фотографии, схемы сопровождают текст с давних времен, однако аудиои видеоэлементы стали включаться в текст лишь несколько лет назад, с приходом такой технической возможности. В связи с этим стало очевидно, что подобные включения пусть и носят зачастую ком- плементарный характер (в случае исследуемых инструкций дело обстоит именно так), все же придают тексту определенную смысловую целостность, задействуя различные каналы передачи информации, усиливают потенциал инструкции, гарантируют особую эффективность выполнения ее функций. Среди инструкций к настольным играм примеров использования аудио и видео в качестве части тек- 
ста пока крайне мало, однако, полагаем, это лишь вопрос времени.

На рисунке 11 представлен фрагмент инструкции, отсылающий игрока к видеочасти текста посредством ссылки на интернет-ресурс. Пример инструкции, показанный на рисунке 12, также со- держит ссылку на видео, в этот раз в виде QR-кода. Считаем необходимым еще раз заострить внимание на том, что данные видеофрагменты носят факультативный характер, инструкция будет понята и без них, но с их помощью инструкция будет более эффективна, да и эффектна.

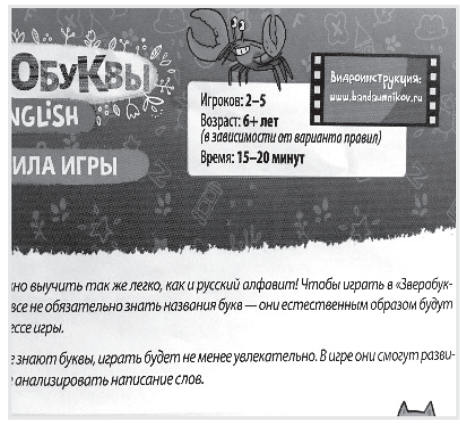

Рис. 11. Фрагмент инструкции настольной игры «Зверобуквы English»

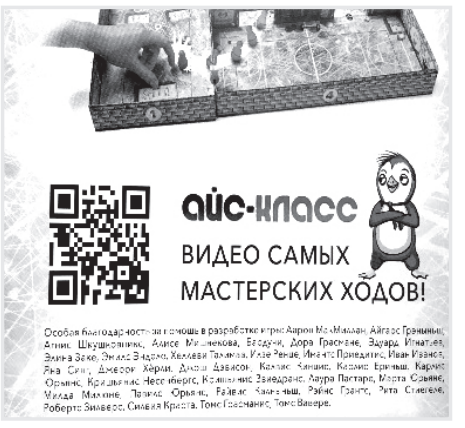

Рис. 12. Фрагмент инструкции настольной игры Брайана Гомеса «Айс-класс»
Сам текст инструкции (его вербальная часть) может быть также дополнен визуальными характеристиками. Значимыми тут будут размер и тип шрифта, цвет букв, разнообразные способы выделения слова внутри фразы (полужирное или курсивное начертание, подчеркивание). За примерами обратимся к рисункам 13, 14. Цели такого исполнения текста все те же: облегчить восприятие текста, сделать его более графичным, а значит, более читаемым.

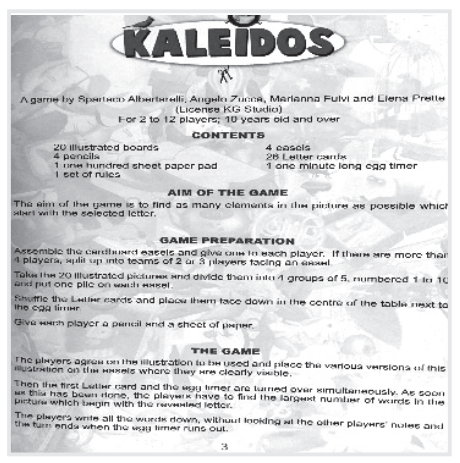

Рис. 13. Фрагмент инструкции настольной игры Спартако Альбертарелли, Анжело Зукки, Марианны Фульви и Елены Претте «Kaleidos»

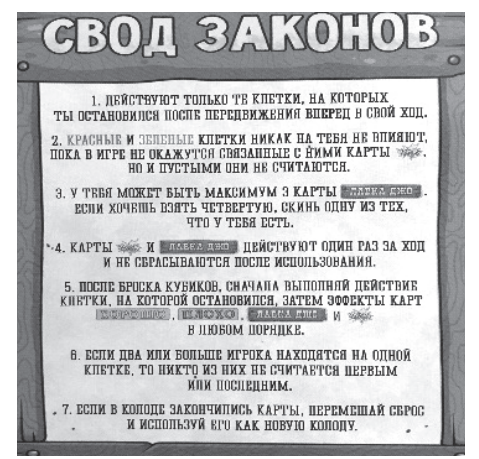

Рис. 14. Фрагмент инструкции настольной игры Игоря Виденкова «Большая бродилка»
Каждая отдельно взятая инструкция может содержать какой-то один из вышеуказанных элементов или несколько элементов, объединенных в целый набор средств, обращающихся к реципиенту и передающих информацию по разным каналам. Следует отметить, что один лишь количественный показатель не может служить гарантом исполнения инструкцией своих функций - доходчиво, однозначно и за минимальное количество времени разъяснить правила игры. Дело всегда в качестве, то есть если подобный гибридный текст содержит помимо вербального компонента еще и иллюстрацию и даже схему, этого может быть недостаточно, если все эти элементы представляют собой разрозненное множество, как и минимальный набор невербальных элементов необязательно представляет собой пример неудачной работы авторов игры. Однако следует признать, что при должном качестве исполнения иллюстраций, схематических изображений и других невербальных компонентов инструкции, которые действительно находятся во взаимодействии друг с другом и гармонично друг друга дополняют, наличие нескольких таких компонентов только улучшают 
качество подачи информации, усиливают эффективность такого рода креолизованных текстов. На рисунках 15 и 16 представлены удачные при- меры сочетания разнообразных невербальных компонентов креолизованного текста инструкции к настольной игре.

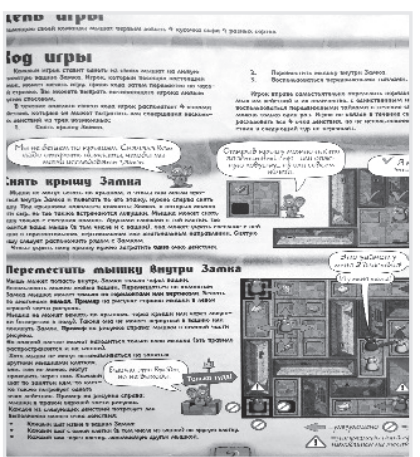

Рис. 15. Фрагмент инструкции настольной игры Йенса-Петера Шлимана и Бернарда Вебера «Сырный замок»

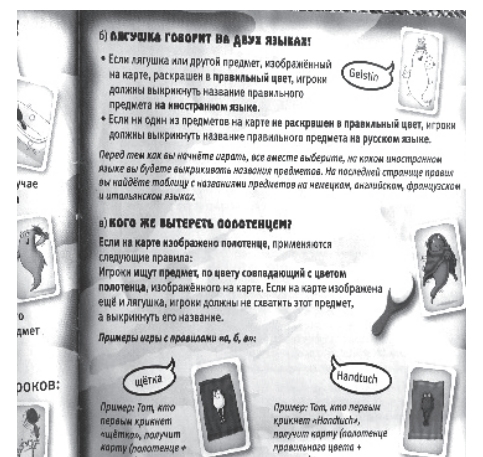

Рис. 16. Фрагмент инструкции настольной игры Жака Цаймета «Барамелька»
В данной статье уже упоминалась многослойность инструкции. В этой связи следует упомянуть еще и нередкое среди такого рода инструкций представление семантически одного и того же текста в двух разных формах: как его полная и более сжатая версии. Визуально это выглядит как два совершенно разных объекта (две разных брошюры, брошюра и отдельная от нее карточка и т. п.), но, по сути, это один и тот же текст. Цель такого исполнения ясна - в процессе игры иметь под рукой лаконично изложенные, сжатые до нескольких предложений правила. Технически усеченный вариант текста может отличаться от текста-донора. Так, вербальная часть текста полностью выхолащивается, остаются только схемы, иллюстрации. В некоторых случаях, наоборот, во вторичном тексте могут отсутствовать все невербальные элементы, и он (если рассматривать его в отрыве от основного) перестает быть гибридным. Подобную ситуацию можно наблюдать на рисунке 17 - слева полная версия правил игры, справа - сжатое до нескольких предложений описание последовательности действий играющего. На рисунке 18 также представлены полная и краткая версия текста инструкции, но в этом случае первоначальный характер текста не изменился, вторичный текст так и остался креолизованным.

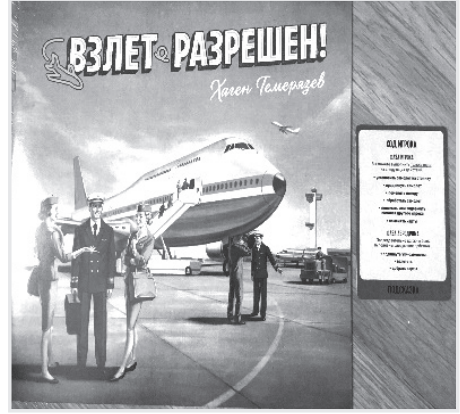

Рис. 17. Фрагмент инструкции настольной игры Хагена Темерязева «Взлет разрешен»

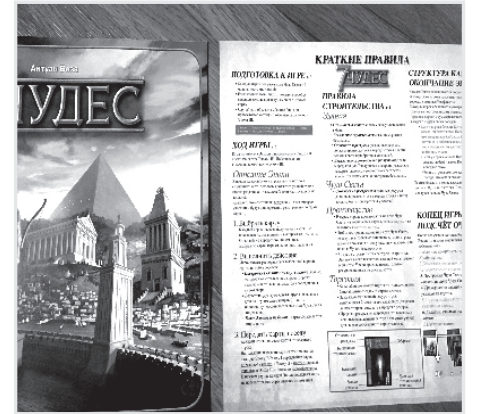

Рис. 18. Фрагмент инструкции настольной игры Антуана Боза «7 чудес»
Процессы и способы креолизации текста были рассмотрены нами на примере инструкций к настольным играм, являющихся, пожалуй, одним из самых первых типов текстов, с которыми приходится иметь дело детям. Не секрет, что мышление вот уже нескольких поколений современных детей работает и воспринимает информацию по клиповому типу, т. е. речь идет об оперировании небольшими порциями данных с ощутимой поддержкой невербального контента. Современному тексту приходится адаптироваться, перевоплощаясь в востребованные формы, ведь только такой текст может быть успешным в плане коммуникации с современным «читателем». 


\section{Библиографический список}

1. Brinker K. Textanalyse. Eine Einführung in Grundbegriffe und Methoden. Berlin, 1992. $163 \mathrm{~S}$.

2. Бернацкая А. А. К проблеме «креолизации» текста: история и современное состояние // Речевое общение: Специализированный вестник. Красноярск: КГУ, 2000. Вып. 3 (11). С. 104-110.

3. Михеев А. В. О некоторых типах взаимодействия изображения и текста // Типы коммуникации и содержательный аспект языка. М., 1987. С. 191-199.

4. Протченко А. В. Типологические и функционально-стилистические характеристики англоязычного путеводителя: автореф. дис. ... канд. филол. наук. Самара, 2006. С. 15-22.

5. Большиянова Л. М. Вербальное сопровождение фотоизображения в современной британской прессе: содержание и структура: автореф. дис. ... канд. филол. наук. Л., 1986. 17 с.

6. Пойманова О. В. Семантическое пространство видеовербального текста: автореф. дис. ... канд. филол. наук. М., 1997. 24 с.

7. Ейгер Г. В. К построению типологии текстов // Лингвистика текста: материалы науч. конф. при МГПИИЯ им. М. Тореза. М., 1974. Ч. 1. С. 103-110.

8. Сорокин Ю. А., Тарасов Е. Ф. Креолизованные тексты и их коммуникативная функция // Оптимизация речевого воздействия. М., 1990. С. 180-186.

9. Педагогическая лингвистика: учеб. пособие для студентов высших учебных заведений / А. Р. Габидуллина. Горловка, 2011. 157 с. 